\title{
A high-fidelity simulation of the C5G7 benchmark by using the parallel ENTER code
}

\author{
Zhenglin Ruan ${ }^{1}$, Haibing Guo ${ }^{*}$ \\ ${ }^{1}$ Institute of Nuclear Physics and Chemistry, China Academy of Engineering Physics \\ Mianyang, Sichuan 621900, China \\ ruanzhenglin@gmail.com,guohaib@foxmail.com
}

\begin{abstract}
In simulation of advanced nuclear reactors, requirements like high precision, high efficiency and convenient to multi-physics coupling are putting forward. The deterministic transport method has the advantage of high efficiency, capable of obtaining detailed flux distribution and efficient in multi-physics coupling, but its accuracy is limited by the homogenized reaction cross-section data and core modelling exactness. The traditional two-steps homogenization strategy may introduce substantial deviation during the assembly calculation. It is possible to conduct a whole core deterministic transport simulation pin-by-pin to achieve higher accuracy, which eliminates the assembly homogenization process. The C5G7 benchmarks were proposed to test the ability of a modern deterministic transport code in analyzing whole core reactor problems without spatial homogenization. Different deterministic code that developed by different methods were applied to the benchmark simulation and some of them solved the benchmark accurately. However, there still exist some drawbacks in the given calculation processes which carried out by some other deterministic transport codes and we could find that the fuel pin cell in the assembly were not exactly geometrically modelled owing to the limit of the code. Consequently, the calculation precision could be improved by utilizing a high-fidelity geometry modelling. In this paper, the C5G7 benchmarks with different control rod position and different configuration were calculated by the finite element $S_{N}$ neutron transport code ENTER [1], and the results were presented after massively parallel computation on TIANHE-II superco mputer. By introducing a large scale high-fidelity unstructured meshes, high fidelity distributions of power and neutron flux were gained and compared with the results from other codes, excellent consistency were observed. To sum up, the ENTER code can meet those new requirements in simulation of advanced nuclear reactors and more works and researches will be implemented for a further improvement.
\end{abstract}

KEYWORDS: Discrete ordinate, Finite element method, ENTER, Whole core transport, C5G7, Massively parallel computation

\section{INTRODUCTION}

With the development of nuclear energy in recent years, a series of advanced nuclear reactors have been built around the world. Gaining more attention on the safety, new demands like high accuracy power distribution and neutron flux distribution are needed to design an advanced reactor system. These demands put new requirements on the tools used to solve the neutron transport equation. In order to get 
high accuracy results, many new neutron transport codes have been developed to replace the previous codes mainly based on the diffusion theory. We usually calculate a large scale 3-D core by using the traditional two step method which may introduce errors during the calculation and finally influence the accuracy of power and flux distributions. So how to eliminate the errors and get a high-fidelity result have been an essential research point and gained much interest from researchers. Owing to the fast development of computer technology, high fidelity calculation method can be used to solve neutron transport equation and simulate a large scale problem.

Besides, the C5G7 MOX benchmark [2] has been proposed by the Nuclear Energy Agency in 2005. The benchmark aims at testing the ability of modern deterministic transport codes to analysis a whole reactor core without spatial homogenization. Several different deterministic transport codes have been tested and the calculation results have been also given in the benchmark. But according to the benchmark book, some codes of them remain some imperfect calculation details which can be improved. Most of the disadvantage is in the mesh generation step. The TORT code [3], PARTISN code [4] and THREEDANT code [5] have done a geometric approximation in generating the pin cell meshes. They set the cylindrical fuel rod into a straight edge polygon. And then the benchmark was calculated. More discussion about the meshes will be present in Section. 2 .

In this paper, the C5G7 MOX benchmark was analyzed by the ENTER code with high fidelity meshes. In Section. 2, the ENTER code and meshes generating method are introduced briefly. In Section. 3 and 4, the calculation results are presented and compared with other codes. In Section. 5, all the works are summarized.

\section{METHODS AND MESHES}

\subsection{General Introduction to the ENTER Code}

The ENTER code was based on the finite element method and $\mathrm{S}_{N}$ neutron transport method. The finite element method had been widely used in the neutron transport analysis. We applied the Galerkin Least Square (GLS) finite element method in ENTER. With the advantage of obtaining quantity distribution field and efficient in multi-physics coupling simulation, the ENTER code could handle the complex problems with large scale geometry construction. And the finite element transport code can massively parallel compute by introduce the parallel adaptive unstructured meshes applications infrastructure JAUMIN [6] to accomplish the domain decomposition and communicate between processes.

As portrayed, the ENTER code can run on the TIANHE-II with more than parallel 1200 processes in this research. Owing to the memory limitation, the order of discrete ordinates was set as $\mathrm{S}_{4}$ and the convergence criteria were set to $1 \times 10^{-4}$ for the flux and $1 \times 10^{-5}$ for the eigenvalue. The power was calculated by setting normalized total power as the number of total fuel pins which was 1056 pins in the core.

\subsection{Discussion of the Meshes Used in the Simulation}

Absolutely, the meshes considerably influenced the calculation accuracy. It should be noted that the codes were usually developed with an uncomplicated geometry processing form previous researches. Some of them, such as the TORT code [3], PARTISN code [4], ARES code [7] and THREEDANT code [5], replaced the curve boundaries with polylines. This kind of treatments were not accuracy enough. The ENTER code can solve the problem with complex geometry by domain decomposition. 
A CAD program was chosen to generate the initial reactor core model and then convert the geometry into an unstructured meshes combination. As shown in Figure 1. and Figure 2., the core area was meshed with quadrilateral unstructured grids and the outer reflector area was meshed from fine grids to coarse grids. We can see the mesh edges were suitable to match the initial geometric boundary. The axial direction was set with rough meshes, which were 6 meshes, 6 meshes, 6 meshes and 8 meshes from the button to the top of the reactor, to increase the calculation speed because we concentrated more on the radial neutron flux distribution. Total number of the unstructured meshes was 1642290 and it would be increased $2 \times 2 \times$ $2=8$ times to 13138320 meshes by the code when calculating to guarantee the accuracy. The coordinate origin of the coordinate system used in this paper was located in the center of the bottom face of the most inner fuel pin.

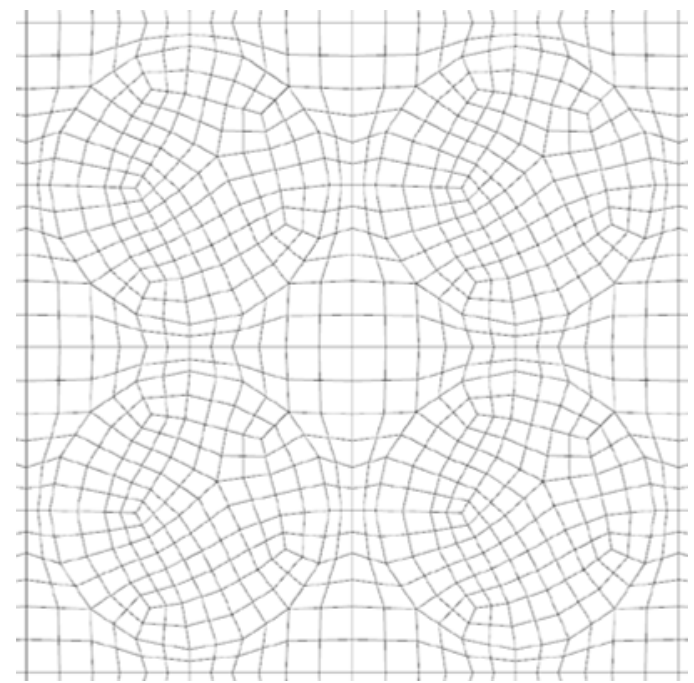

Figure 1. Mesh Composition in Core Area (X-Y, Z=0)

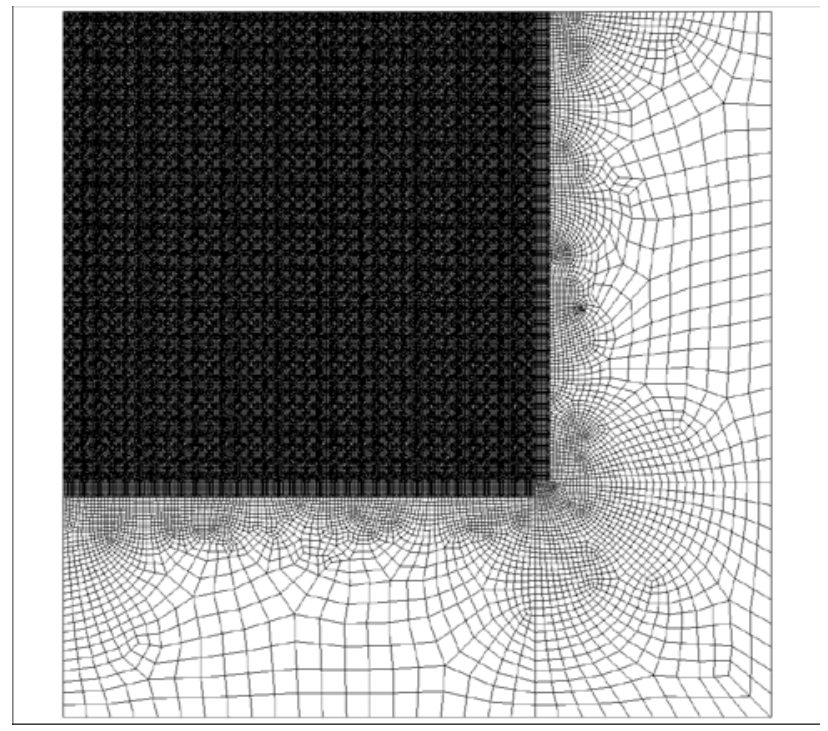

Figure 2. Mesh Composition of the Whole Reactor (X-Y, $\mathrm{Z}=0)$ 


\section{BENCHMARKE DISCRIBUTION}

The C5G7 MOX benchmark described a model of a 1/8 PWR reactor core with vacuum boundary conditions outer the reactor. And two $\mathrm{UO}_{2}$ assemblies and two MOX assemblies with 3 different level of enrichment $(4.3 \%, 7.0 \%, 8.7 \%)$ were set staggered. Each assembly was consist of $17 \times 17$ rods and the size of it was $21.42 \mathrm{~cm} \times 21.42 \mathrm{~cm} \times 42.84 \mathrm{~cm}$. The whole size of the model was $64.24 \mathrm{~cm} \times$ $64.24 \mathrm{~cm} \times 64.24 \mathrm{~cm}$. This benchmark covered three cases characterized by control position: (1) UNRODDED - control rods stayed in reflector above fuel assemblies and the fission chamber should also be modeled in the upper reflector, (2) RODDED A - the control rod was inserted one-third of the inner $\mathrm{UO}_{2}$ fuel assemblies, and (3) RODDED B - the control rod was inserted two-thirds of the inner $\mathrm{UO}_{2}$ fuel assemblies and one-third of the two MOX assemblies.

In the benchmark, the fuel assemblies were split into three axial slices equally. Slice 1, 2, 3 were the lower, middle and upper slice.

As it was shown in the benchmark, seven group macroscopic cross-section of all material, which included the fuel rods, guide tubes, fission chamber and control rods, was provided. All the macroscopic cross-sections were converted into the ENTER coed format.

\section{CALCULATION RESULT}

The ENTER code was used to simulate the whole reactor transport and the pin power distribution, flux distribution and $k_{\text {eff }}$ eigenvalue are calculated. And the pin power distribution and flux distribution were gained from the transport calculation by applying ENTER code. Table I. presented the maximum pin power in slices 1, 2, 3, under the case of UNRODED, RODDED A and RODDED B. All the results were compared with the reference results in the benchmark book [2].

Table I: Results of Maximum Pin Power

\begin{tabular}{|c|c|c|c|c|c|c|}
\hline CASE & $\begin{array}{c}\text { Simulation } \\
\text { Results } \\
\text { (By } \\
\text { ENTER) }\end{array}$ & $\begin{array}{c}\text { Reference } \\
\text { (By } \\
\text { MCNP [8]) }\end{array}$ & $\begin{array}{c}\text { Relative } \\
\text { Error } \\
(\%)\end{array}$ & $\begin{array}{c}\text { Simulation } \\
\text { Results and } \\
\text { Error (\%) } \\
\text { (By } \\
\text { TORT-PSU) }\end{array}$ & $\begin{array}{c}\text { Simulation } \\
\text { Results and } \\
\text { Error (\%) } \\
\text { (By } \\
\text { THREEDANT) }\end{array}$ & $\begin{array}{c}\text { Simulation } \\
\text { Results and } \\
\text { Error (\%) } \\
\text { (By } \\
\text { PARTISN) }\end{array}$ \\
\hline UNRODDED & 2.4824 & 2.481 & 0.06 & $\begin{array}{c}2.485 \\
(0.14)\end{array}$ & $\begin{array}{c}2.506 \\
(1.10)\end{array}$ & $\begin{array}{c}2.486 \\
(0.21)\end{array}$ \\
\hline $\begin{array}{c}\text { UNRODDED } \\
\text { in slice 1 }\end{array}$ & 1.1290 & 1.108 & 1.90 & $\begin{array}{c}1.113 \\
(0.46)\end{array}$ & $\begin{array}{c}1.121 \\
(1.15)\end{array}$ & $\begin{array}{c}1.112 \\
(0.36)\end{array}$ \\
\hline $\begin{array}{c}\text { UNRODDED } \\
\text { in slice 2 }\end{array}$ & 0.9011 & 0.882 & 2.17 & $\begin{array}{c}0.884 \\
(0.18)\end{array}$ & $\begin{array}{c}0.891 \\
(1.02)\end{array}$ & $\begin{array}{c}0.884 \\
(0.22)\end{array}$ \\
\hline $\begin{array}{c}\text { UNRODDED } \\
\text { in slice 3 }\end{array}$ & 0.5067 & 0.491 & 3.20 & $\begin{array}{c}0.488 \\
(-0.66)\end{array}$ & $\begin{array}{c}0.494 \\
(0.64)\end{array}$ & $\begin{array}{c}0.490 \\
(-0.14)\end{array}$ \\
\hline RODDED A & 2.2418 & 2.253 & -0.50 & $\begin{array}{c}2.256 \\
(0.10)\end{array}$ & $\begin{array}{c}2.275 \\
(0.95)\end{array}$ & $\begin{array}{c}2.253 \\
(-0.03)\end{array}$ \\
\hline $\begin{array}{c}\text { RODDED A } \\
\text { in slice 1 }\end{array}$ & 1.2136 & 1.197 & 1.39 & $\begin{array}{c}1.200 \\
(0.28)\end{array}$ & $\begin{array}{c}1.211 \\
(1.15)\end{array}$ & $\begin{array}{c}1.202 \\
(0.39)\end{array}$ \\
\hline
\end{tabular}




\begin{tabular}{|c|c|c|c|c|c|c|}
\hline $\begin{array}{c}\text { RODDED A } \\
\text { in slice 2 }\end{array}$ & 0.8409 & 0.832 & 1.07 & $\begin{array}{c}0.830 \\
(-0.14)\end{array}$ & $\begin{array}{c}0.840 \\
(1.07)\end{array}$ & $\begin{array}{c}0.831 \\
(0.00)\end{array}$ \\
\hline $\begin{array}{c}\text { RODDED A } \\
\text { in slice 3 }\end{array}$ & 0.3104 & 0.304 & 2.11 & $\begin{array}{c}0.305 \\
(0.43)\end{array}$ & $\begin{array}{c}0.306 \\
(0.61)\end{array}$ & $\begin{array}{c}0.300 \\
(-1.27)\end{array}$ \\
\hline RODDED B & 1.8248 & 1.835 & 2.34 & $\begin{array}{c}1.836 \\
(0.08)\end{array}$ & $\begin{array}{c}1.847 \\
(0.68)\end{array}$ & $\begin{array}{c}1.822 \\
(-0.67)\end{array}$ \\
\hline $\begin{array}{c}\text { RODDED B } \\
\text { in slice 1 }\end{array}$ & 1.2281 & 1.200 & 2.30 & $\begin{array}{c}1.197 \\
(-0.22)\end{array}$ & $\begin{array}{c}1.214 \\
(1.19)\end{array}$ & $\begin{array}{c}1.204 \\
(0.32)\end{array}$ \\
\hline $\begin{array}{c}\text { RODDED B } \\
\text { in slice 1 }\end{array}$ & 0.5614 & 0.554 & 1.34 & $\begin{array}{c}0.554 \\
(0.02)\end{array}$ & $\begin{array}{c}0.556 \\
(0.36)\end{array}$ & $\begin{array}{c}0.545 \\
(-1.58)\end{array}$ \\
\hline $\begin{array}{c}\text { RODDED B } \\
\text { in slice 1 }\end{array}$ & 0.2203 & 0.217 & 1.52 & $\begin{array}{c}0.216 \\
(-0.42)\end{array}$ & $\begin{array}{c}0.215 \\
(-0.63)\end{array}$ & $\begin{array}{c}0.208 \\
(-3.94)\end{array}$ \\
\hline
\end{tabular}

The relative percent errors of the maximum pin power in Table I. were range from $0.06 \%$ to $3.20 \%$. The magnitudes of maximum pin power from ENTER code were notably bigger than the reference results and the results of TORT, THREEDANT and PARTISN. It might be caused by the defect of the least squares finite element method when solving integral assembly matrix. More work would be done to improve the code and more results would be calculated and discussed.

The power of each assembly was present in Table II. And all the relative percent errors of assembly power were lower than $1.69 \%$. These comparisons proved that the ENTER code did have the ability in calculating a large scale transport problem with less approximation. To gain a better result, higher quadrature order and finer mesh would be used in next work.

Table II: Results of Assembly Power

\begin{tabular}{|c|c|c|c|c|c|c|}
\hline Assembly & $\begin{array}{c}\text { Simulation } \\
\text { Results } \\
(\mathrm{By} \\
\text { ENTER) }\end{array}$ & $\begin{array}{c}\text { Reference } \\
(\mathrm{By} \\
\text { MCNP) }\end{array}$ & $\begin{array}{c}\text { Relative } \\
\text { Error } \\
(\%)\end{array}$ & $\begin{array}{c}\text { Simulation } \\
\text { Results and } \\
\text { Error (\%) } \\
(\text { By } \\
\text { TORT-PSU) }\end{array}$ & $\begin{array}{c}\text { Simulation } \\
\text { Results and } \\
\text { Error (\%) } \\
\text { (By } \\
\text { THREEDANT) }\end{array}$ & $\begin{array}{c}\text { Simulation } \\
\text { Results and } \\
\text { Error (\%) } \\
\text { (By } \\
\text { PARTISN) }\end{array}$ \\
\hline $\begin{array}{c}\text { UNRODDED } \\
\text { Inner UO } 2\end{array}$ & 499.48 & 491.2 & 1.69 & $\begin{array}{c}491.7 \\
(0.10)\end{array}$ & $\begin{array}{c}494.7 \\
(0.70)\end{array}$ & $\begin{array}{c}491.8 \\
(0.13)\end{array}$ \\
\hline $\begin{array}{c}\text { UNRODDED } \\
\text { MOX }\end{array}$ & 209.20 & 212.7 & -1.65 & $\begin{array}{c}212.5 \\
(-0.10)\end{array}$ & $\begin{array}{c}211.0 \\
(-0.81)\end{array}$ & $\begin{array}{c}212.4 \\
(-0.13)\end{array}$ \\
\hline $\begin{array}{c}\text { UNRODDED } \\
\text { Outer UO } 2\end{array}$ & 138.12 & 139.4 & -0.92 & $\begin{array}{c}139.3 \\
(-0.05)\end{array}$ & $\begin{array}{c}139.4 \\
(0.00)\end{array}$ & $\begin{array}{c}139.3 \\
(-0.05)\end{array}$ \\
\hline $\begin{array}{c}\text { RODDED A } \\
\text { Inner UO }\end{array}$ & 465.75 & 461.2 & 0.99 & $\begin{array}{c}461.7 \\
(0.12)\end{array}$ & $\begin{array}{c}464.6 \\
(0.72)\end{array}$ & $\begin{array}{c}461.1 \\
(-0.01)\end{array}$ \\
\hline $\begin{array}{c}\text { RODDED A } \\
\text { MOX }\end{array}$ & 218.91 & 221.7 & -1.26 & $\begin{array}{c}221.5 \\
(-0.11)\end{array}$ & $\begin{array}{c}220.0 \\
(-0.77)\end{array}$ & $\begin{array}{c}221.6 \\
(-0.04)\end{array}$ \\
\hline $\begin{array}{c}\text { RODDED A } \\
\text { Outer UO }\end{array}$ & 152.43 & 151.4 & 0.68 & $\begin{array}{c}151.3 \\
(-0.06)\end{array}$ & $\begin{array}{c}151.5 \\
(0.06)\end{array}$ & $\begin{array}{c}151.6 \\
(0.16)\end{array}$ \\
\hline $\begin{array}{c}\text { RODDED B } \\
\text { Inner UO } 2\end{array}$ & 401.16 & 395.4 & 1.46 & $\begin{array}{c}395.4 \\
(0.00)\end{array}$ & $\begin{array}{c}397.5 \\
(0.53)\end{array}$ & $\begin{array}{c}393.6 \\
(-0.47)\end{array}$ \\
\hline $\begin{array}{c}\text { RODDED B } \\
\text { MOX }\end{array}$ & 233.43 & 236.6 & -1.34 & $\begin{array}{c}237.9 \\
(0.54)\end{array}$ & $\begin{array}{c}235.0 \\
(-0.68)\end{array}$ & $\begin{array}{c}236.8 \\
(0.08)\end{array}$ \\
\hline RODDED B & 187.98 & 187.3 & 0.36 & 189.0 & 188.5 & 188.8 \\
\hline
\end{tabular}




\begin{tabular}{|l|l|l|l|l|l|l|}
\hline Outer $\mathrm{UO}_{2}$ & & & & $(0.88)$ & $(0.59)$ & $(0.79)$ \\
\hline
\end{tabular}

The 3-D high precision power density distribution and flux distribution were also gained and the 2-D results in specific cross-sections of the UNRODDED, RODDEDA and RODDEDB cases were showed in Figure 3., Figure 4. and Figure 5. From Figure 3-5, it was obviously that the ENTER code could provide a high fidelity solution to the 3-D transport problems. And with the control rods injecting into the reactor, the pin power in the bottom of the core was increasing and the flux was decreasing as expected.

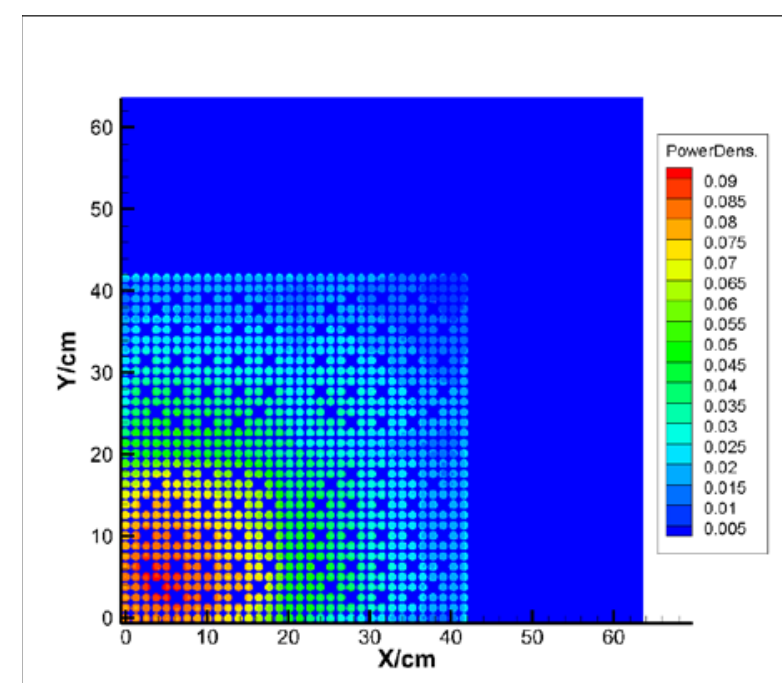

a. Power Density Distribution in UNRODDED Case (X-Y, Z=0)

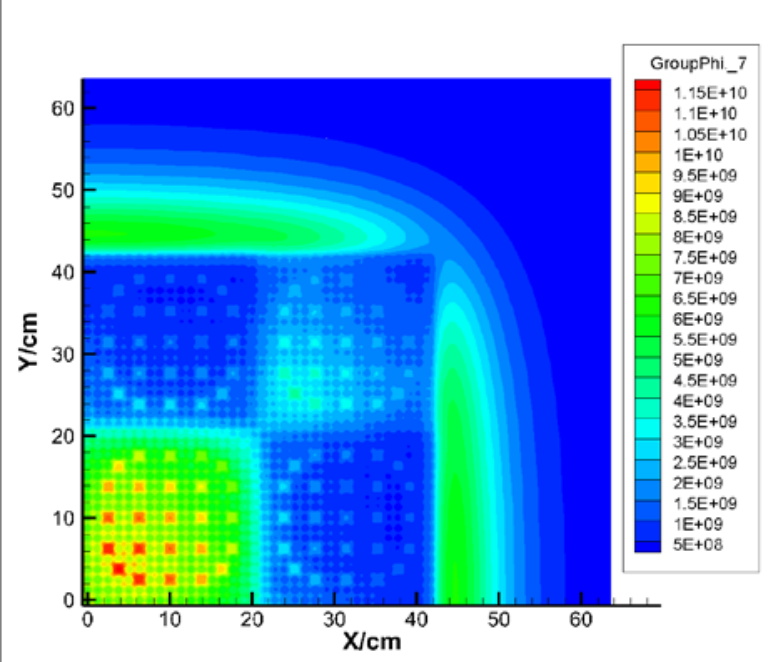

c. Flux Distribution of Group 7 in UNRODDED Case $(\mathrm{X}-\mathrm{Y}, \mathrm{Z}=0)$

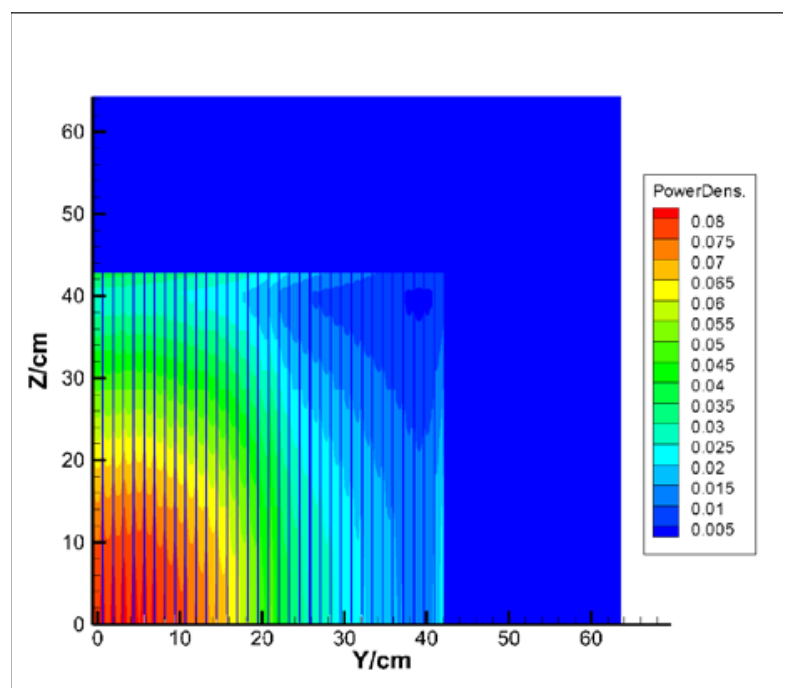

b. Power Density Distribution in UNRODDED Case (Y-Z, X=0)

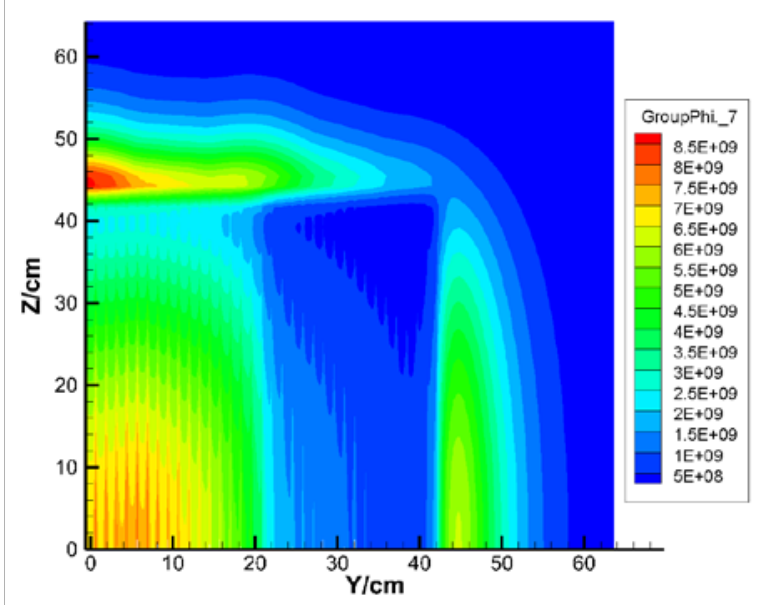

d. Flux Distribution of Group 7 in UNRODDED Case (Y-Z, X=0)

Figure 3. Power Density Distribution and Flux Distribution of Group 7 Form $X-Y$ and $Y-Z$ Cross-Section in UNRODDED Case 


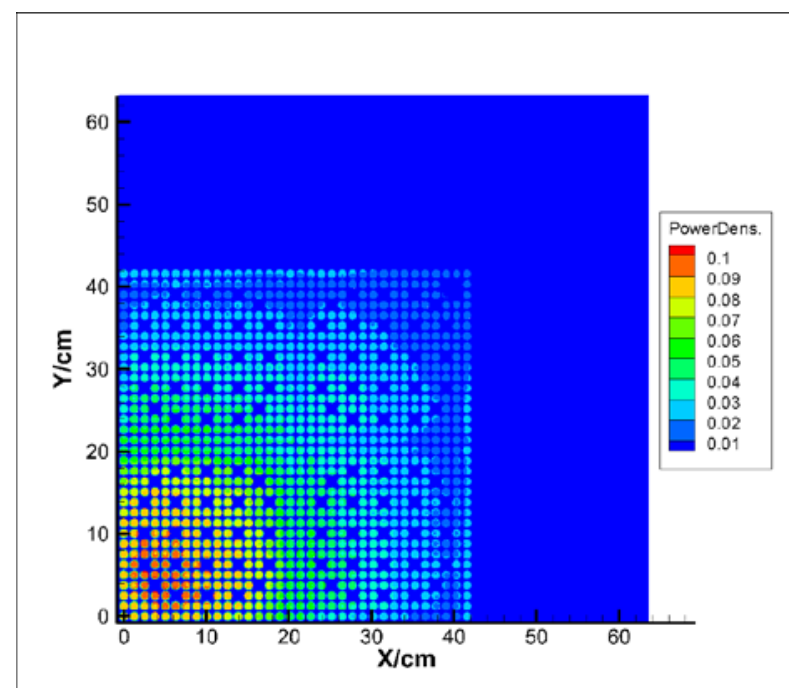

a. Power Density Distribution in RODDEDA Case (X-Y, Z=0)

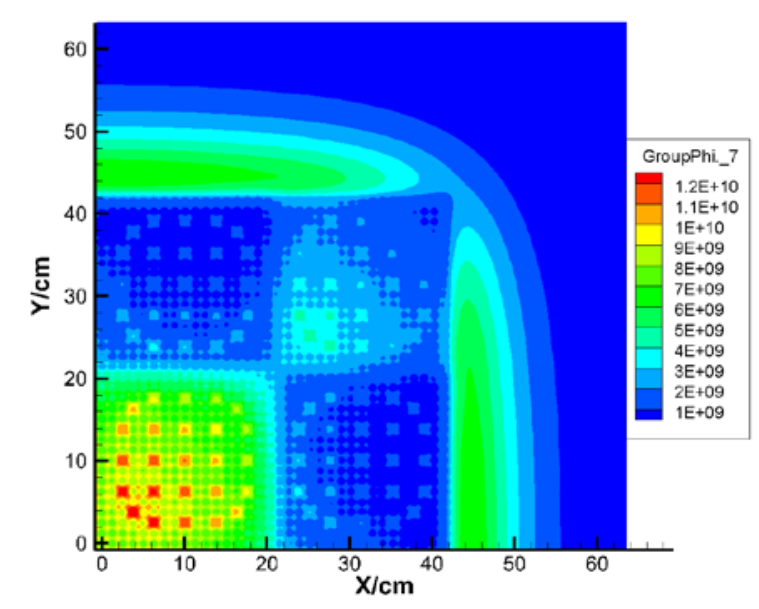

c. Flux Distribution of Group 7 in RODDEDA Case (X-Y, Z=0)

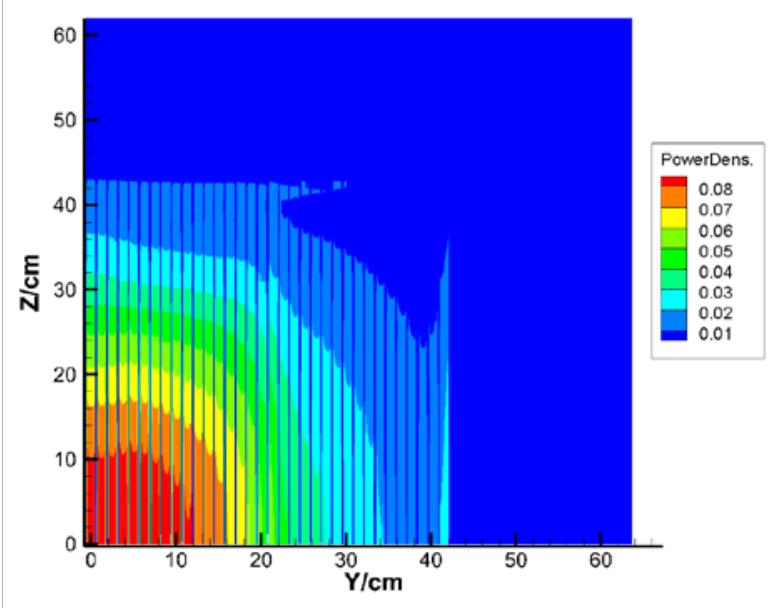

b. Power Density Distribution in RODDEDA Case (Y-Z, $\mathrm{X}=0$ )

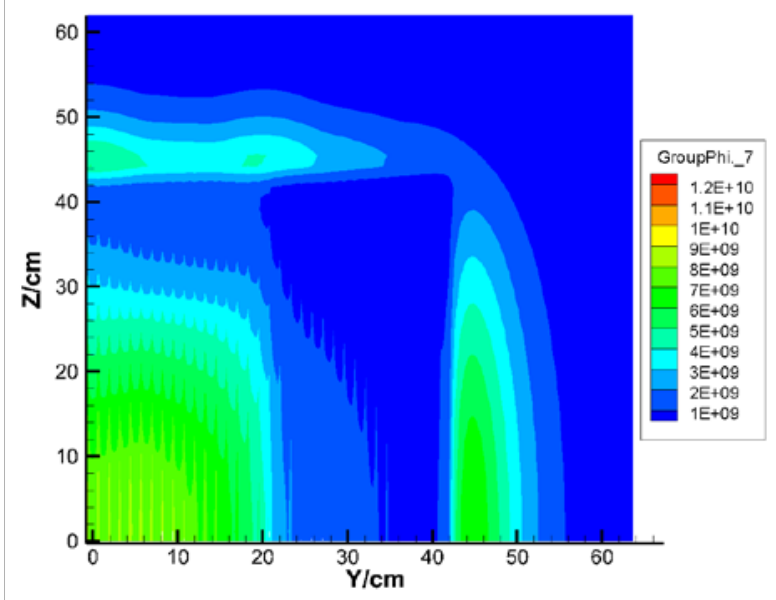

d. Flux Distribution of Group 7 in RODDEDA Case (Y-Z, X=0)

Figure 4. Power Density Distribution and Flux Distribution of Group 7 Form X-Y and Y-Z Cro ss-Section in RODEDDA Case 


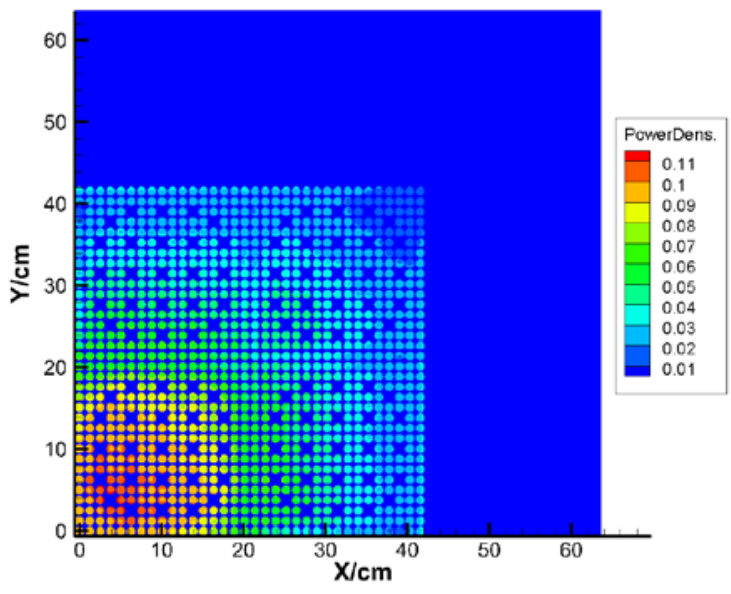

a. Power Density Distribution in RODDEDB Case $(\mathrm{X}-\mathrm{Y}, \mathrm{Z}=0)$

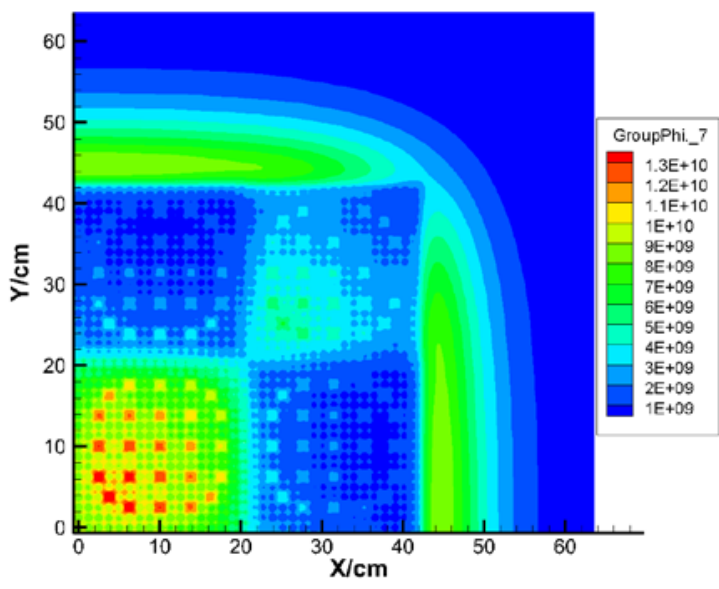

c. Flux Distribution of Group 7 in RODDEDB Case $(\mathrm{X}-\mathrm{Y}, \mathrm{Z}=0)$

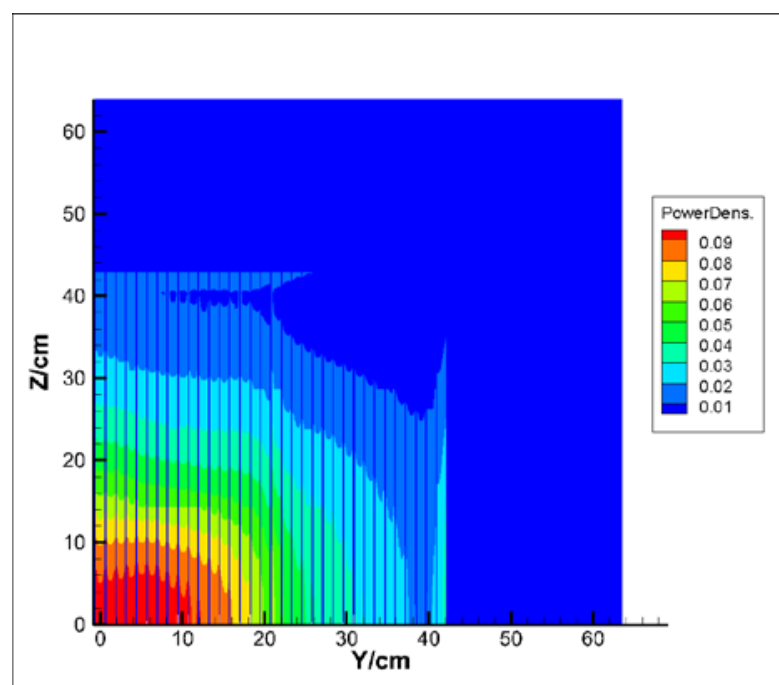

b. Power Density Distribution in RODDEDB Case (Y-Z, $\mathrm{X}=0$ )

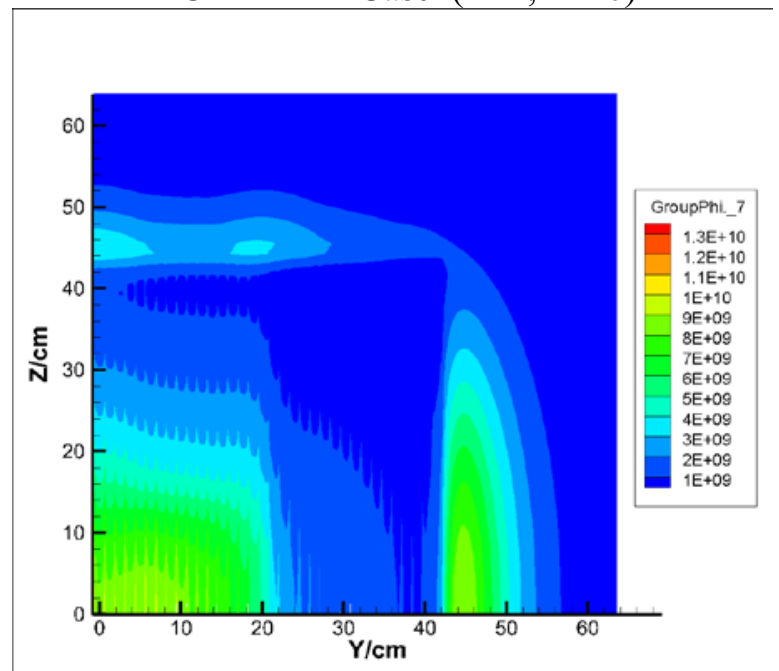

d. Flux Distribution of Group 7 in RODDEDB Case (Y-Z, X=0)

Figure 5. Power Density Distribution and Flux Distribution of Group 7 Form X-Y and Y-Z Cross-Section in RODDEDB Case

\section{CONCLUSIONS}

The ENTER code was tested by simulating the C5G7 MOX benchmark. The pin power distribution, power density distribution and flux distribution were presented and discussed in Section. 4. The relative percent errors of the maximum pin power were lower than $3.20 \%$ and the relative percent errors of assembly power are lower than $1.69 \%$. These results matched well when compared with the reference from the benchmark book and other deterministic code. The detailed high precision power density distribution and flux distribution were parented inside the core by many 2-D figures and these figures gave an intuitive performance of the power and flux changing in condition of different control rod 
positions. There was no doubt that the application of high fidelity meshes should be paid more attention on it to maintain the demanded calculation accuracy in a large scale reactor simulation.

In conclusion, the ENTER code has the advantage of handling complex geometry problem with no approximations based on the high fidelity unstructured meshes. It means that the code can universally apply to various kinds of reactor. Secondly, all the calculations were operated on the supercomputer with 1200 processes and the ENTER code was proved to have an excellent parallel operation capability. But there still remained some problems in this research. More research will be done to improve the ENTER code and to give more results explicitly.

\section{REFERENCES}

1. Haibing Guo, Hongwen Huang, Jimin Ma, et.al, "Parallelization of the finite element $\mathrm{S}_{\mathrm{N}}$ neutron transport simulation based on domain decomposition," Atomic Energy Science and Technology, 2020 (In Press, in Chinese)

2. NEA, "Benchmark on Deterministic Transport Calculations Without Spatial Homogenization," OECD. (2005):

3. Seubert, A., W. Zwermann and S. Langenbuch, "Solution of the C5G7 3-D extension benchmark by the SN code TORT," Progress in Nuclear Energy, 48(5), pp. 432-438. (2006).

4. Dahl, J.A., "PARTISN results for the OECD/NEA 3-D extension C5G7 MOX benchmark," Progress in Nuclear Energy, 48(5), pp. 401-409. (2006).

5. Kim, H., C.Y. Han and J.K. Kim, "THREEDANT calculations for the 3-D extension C5G7 MOX benchmark," Progress in Nuclear Energy, 48(5): pp. 424-431 (2006).

6. Q. Liu, W. Zhao, J. Cheng, Z. Mo, A. Zhang and J. Liu, "A Programming Framework for Large Scale Numerical Simulations on Unstructured Mesh," 2016 IEEE 2nd International Conference on Big Data Security on Cloud (BigDataSecurity), IEEE International Conference on High Performance and Smart Computing (HPSC), and IEEE International Conference on Intelligent Data and Security (IDS), New York, 2016, pp. 310-315.

7. Zhang, L., et al., "Calculation of the C5G7 3-D extension benchmark by ARES transport code," Nuclear Engineering and Design, 318, pp. 231-238 (2017).

8. Reda, S.M. and E.A. Amin, "Calculation of the NEA C5G7 MOX benchmark with MCNP5," Progress in Nuclear Energy, 76, pp. 244-254 (2014). 